\title{
Berat Bayi Lahir Rendah Berdasarkan Paritas, Ketuban Pecah Dini dan Hipertensi
}

\section{Low birth weight Based on Parity, Premature Rupture of Membranes and Hypertension}

\author{
Septika Zahra ${ }^{1}$, Prasetyowati $^{2, \bigotimes}$, Yuliawati $^{2}$ \\ ${ }^{1}$ Dinas Kesehatan Kota Metro, Lampung, Indonesia \\ ${ }^{2}$ Jurusan Kebidanan, Politeknik Kesehatan Tanjung Karang, Indonesia \\ ${ }^{凶}$ Corresponding author: Septika.zahra@gmail.com
}

Kata kunci:
Paritas;
Ketuban pecah dini;
Hipertensi;
BBLR.

Keywords:

Parity;

Premature rupture of membranes;

Hypertension;

$L B W$.

\begin{abstract}
Abstrak
Latar belakang: Berat bayi lahir rendah (BBLR) merupakan faktor utama peningkatan mortalitas dan morbiditas pada neonatus, bayi yang memberikan dampak jangka panjang terhadap kehidupan di masa depan. Tujuan: Tujuan penelitian untuk mengetahui hubungan antara paritas, ketuban pecah dini dan hipertensi dengan BBLR di RS Mardi Waluyo Metro Tahun 2016. Metode: Penelitian ini menggunakan desain cross sectional. Sampel penelitian berjumlah 302 bayi baru lahir yang diambil dengan teknik quota sampling. Variabel independen penelitian meliputi paritas, ketuban pecah dini dan hipertensi, sedangkan variabel dependen, yaitu bayi baru lahir rendah. Analisis bivariat menggunakan uji chi square. Hasil: Hasil penelitian menunjukkan prevalensi BBLR 25,5\% dari 302 bayi dan terdapat hubungan BBLR dengan paritas $(\mathrm{p}=0,024)$, ketuban pecah dini $(p=0,010)$ dan hipertensi $(p=0,000)$. Simpulan: Simpulan penelitian ini adalah faktor paritas, ketuban pecah dini dan hipertensi meningkatkan prevalensi BBLR.
\end{abstract}

\begin{abstract}
Background: Low birth weight (LBW) are a major factor in increasing mortality and morbidity in neonates, infants who have a long-term impact on life in the future. Purpose: The aim of the study was to determine the relationship between parity, premature rupture of membranes and hypertension with LBW at Mardi Waluyo Metro Hospital in 2016. Methods: This study uses a cross sectional design. The study sample consisted of 302 newborns taken by quota sampling technique. The independent variables of the study included parity, premature rupture of membranes and hypertension, while the dependent variable was low newborns. Bivariate analysis using chi square test. Results: The results showed LBW prevalence of $25.5 \%$ of 302 infants and there was a correlation between $L B W$ and parity $(p=$ $0.024)$, premature rupture of membranes $(p=0.010)$ and hypertension $(p=0.000)$. Conclusions: The conclusions of this study are parity, premature rupture of membranes and hypertension increasing the prevalence of $L B W$.
\end{abstract}

Copyright $@ 2018$ Jurnal Kesehatan Metro Sai Wawai. All rights reserved. 


\section{Pendahuluan}

Bayi berat lahir rendah (BBLR) merupakan faktor utama dalam peningkatan mortalitas, morbiditas dan ketidakmampuan lebih dalam aktifitas karena keterbatasan fisik/mental pada neonatus, bayi dan anak serta memberikan dampak jangka panjang terhadap kehidupan di masa depan. Berdasarkan program pemerintah Sustainable Development Goals (SDG's) bahwa pada tahun 2030, adalah menurunkan Angka Kematian Neonatal (AKN) hingga 12 per 1.000 kelahiran hidup (KH) (Kemenkes RI, 2015).

Hasil Survei Demografi dan Kesehatan Indonesia (SDKI) tahun 2012 diperoleh AKN di Indonesia sebesar 19 per $1.000 \mathrm{KH}$. AKN ini masih cukup tinggi dari target SDG's sebesar 12 per 1.000 KH hingga tahun 2030. Menurut SDKI 2012 di Provinsi Lampung pada tahun 2012 AKN 20 per 1000 KH. Adapun AKN berdasarkan laporan Seksi Kesehatan Keluarga Dinas Kota Metro pada tahun 2015 sebesar 6 per 1000 KH (Dinas Kesehatan Kota Metro, 2016), sedangkan di RS Mardi Waluyo pada bulan Januari-Oktober tahun 2016 tercatat jumlah kematian neonatal sebanyak 15 kasus (9,7\%) dari 154 kasus BBLR ( (RS MardiWaluyo Metro, 2016). Penyebab kematian neonatus di Provinsi Lampung tahun 2013 disebabkan karena asfiksia sebesar 37,14\%, BBLR , kelainan kongenital sebesar 11,87\% dan infeksi 3,39\% (Dinas Kesehatan Provinsi Lampung, 2014).

BBLR hingga saat ini masih menjadi masalah di bidang kesehatan perinatal. Menurut WHO BBLR dengan kejadian tertinggi terdapat di Asia Tengah-Selatan 27,1\% dan terendah di eropa 6,4\%. Angka kejadian BBLR di Indonesia sangat bervariasi antara satu daerah dengan daerah lain, menurut hasil Riskesdas tahun 2013 jumlah kasus BBLR di Indonesia sebesar 475.833 kasus $(10,2 \%)$ dari 4665.025 bayi. Di Provinsi Lampung tahun 2013 jumlah kasus BBLR berjumlah 12.600 kasus $(8,0 \%)$ dari 157.385 bayi (Kementerian Kesehatan RI, 2014), sedangkan untuk Kota Metro jumlah kasus bayi dengan BBLR pada tahun 2015 menjadi 237 kasus $(8,21 \%)$ dari 2.888 bayi (Dinas Kesehatan Kota Metro, 2016). Di RS Mardi Waluyo Metro pada bulan Januari-Oktober tahun 2016 terdapat bayi dengan kasus BBLR berjumlah 12,8\% dari 1196 bayi baru lahir, angka ini lebih tinggi bila dibandingkan dengan kejadian BBLR di RS Muhammadiyah Metro yang berjumlah 11,5\% dari 1783 bayi baru lahir. Hasil studi pendahuluan RS Mardi Waluyo Metro pada bulan Oktober-November sebesar 40 kasus BBLR.

BBLR disebabkan oleh faktor ibu adalah gizi saat hamil yang kurang, jarak hamil dan bersalin terlalu dekat, hipertensi. Faktor kehamilan seperti hamil dengan hidramnion, hamil ganda, perdarahan antepartum, komplikasi kehamilan: preeklamsia/eklamsi, ketuban pecah dini. Faktor janin, seperti cacat bawaan, infeksi dalam rahim (Dinas Kesehatan Kota Metro, 2016). Kejadian BBLR berdasarkan hasil penelitian Supartini di RSUD Ahmad Yani Kota Metro menunjukan bahwa proporsi paritas berisiko yang melahirkan bayi dengan BBLR sebanyak $37 \%$ dengan analisa menunjukan adanya hubungan paritas dengan BBLR. Penelitian lain oleh Afrina menunjukkan bahwa ibu dengan hipertensi yang melahirkan bayi dengan BBLR sebesar 26,2\% dengan hasil penelitian menunjukkan adanya hubungan hipertensi dengan kejadian BBLR (Afrina, 2013). Berdasarkan penelitian Humaeroh di PKU Muhammadiyah Bantul Yogyakarta menunjukkan kejadian KPD sebanyak 16,67\% dengan hasil penelitian menunjukkan terdapat hubungan ketuban pecah dini dengan BBLR (Humaeroh, 2014). Artikel ini memberikan informasi dari hasil penelitian yang bertujuan menganalisis hubungan antara paritas, ketuban pecah dini dan hipertensi dengan BBLR di RS Mardi Waluyo Metro Tahun 2016.

\section{Metode}

Penelitian ini merupakan penelitian analitik dengan rancangan cross sectional. Rancangan penelitian digunakan untuk membuktikan hubungan paritas, ketuban pecah dini dan hipertensi dengan BBLR. Populasi dalam penelitian ini adalah seluruh bayi baru lahir di RS Mardi Waluyo Metro pada bulan Januari-Desember 2016 sebanyak 1220 bayi baru lahir. Sampel dihitung berdasarkan rumus 
sederhana oleh Solvin dengan $\mathrm{N}=1220$ dan $\mathrm{d}=0,05$. Sehingga, diperoleh sampel berjumlah 302 bayi yang diambil dengan teknik quota sampling. Variabel independen meliputi paritas, ketuban pecah dini dan hipertensi, sedangkan variabel dependen, yaitu bayi baru lahir rendah.

Pengumpulan data dilakukan pada bulan April 2017 dengan cara studi dokumentasi yang bersumber rekam medik di RS Mardi Waluyo Metro yang memenuhi syarat penelitian. Alat ukur penelitian menggunakan check list yang disusun sesuai konsep teori variabel penelitian yang diteliti dan dianalisis. Data yang telah dikumpulkan dilakukan analisis univariat dan bivariat. Analisis bivariat digunakan untuk menganalisis kejadian BBLR yang diduga berhubungan atau berkorelasi dengan paritas, ketuban pecah dini dan hipertensi menggunakan uji chi square dengan tingkat kepercayaan 95\% dan tingkat kemaknaan $(\alpha) 0,05$.

\section{Hasil}

\section{Gambaran responden}

Hasil penelitian pada tabel 1 menunjukkan gambaran responden dari 302 bayi baru lahir, terdapat 25,5\% BBLR, 48\% dengan paritas berisiko ( 1 dan $\geq 4), 50,3 \%$ mengalami KPD dan 36,8\% mengalami Hipertensi.

Tabel 1.

Distribusi BBL, paritas, KPD dan hipertensi

\begin{tabular}{llcc}
\hline \multicolumn{1}{c}{ Variabel } & \multicolumn{1}{c}{ Karegori } & $\mathbf{n = 3 0 2}$ & \% \\
\hline Berat Lahir Bayi & BBLR $(<2500$ gr $)$ & 77 & 25,5 \\
\multirow{2}{*}{ Paritas } & Normal $(\geq 2500$ gr $)$ & 225 & 74,5 \\
\multirow{2}{*}{ Ketuban Pecah Dini } & Berisko & 145 & 48,0 \\
& Tidak Berisiko & 157 & 52,0 \\
Tekanan Darah & KPD & 152 & 50,3 \\
& Tidak KPD & 150 & 49,7 \\
& Hipertensi & 111 & 36,8 \\
& Tidak Hipertensi & 191 & 63,2 \\
\hline
\end{tabular}

\section{Analisis bivariat}

Hasil analisis bivariat menggunakan uji chi square pada tabel 2 memperoleh hasil terdapat hubungan paritas $(\mathrm{p}=0,024), \mathrm{KPD}(\mathrm{p}=0,010)$ dan hipertensi $(\mathrm{p}=0,000)$ dengan kejadian BBLR di RS Mardi Waluyo Kota Metro tahun 2016.

Tabel 2.

Distribusi hubungan paritas, KPD dan hipertensi dengan kejadian BBLR

\begin{tabular}{|c|c|c|c|c|c|c|c|}
\hline \multirow{3}{*}{ Variabel } & \multicolumn{4}{|c|}{ Bayi Baru Lahir } & \multirow{2}{*}{\multicolumn{2}{|c|}{ Jumlah }} & \multirow{3}{*}{$\begin{array}{c}P \\
\text { Value }\end{array}$} \\
\hline & \multicolumn{2}{|c|}{ BBLR } & \multicolumn{2}{|c|}{ Tidak BBLR } & & & \\
\hline & $\mathrm{n}=77$ & $\%$ & $\mathrm{n}=\mathbf{2 2 5}$ & $\%$ & $\mathrm{n}=302$ & $\%$ & \\
\hline \multicolumn{8}{|l|}{ Paritas } \\
\hline Berisiko (1 dan $\geq 4)$ & 46 & 59,7 & 99 & 44,0 & 145 & 100 & \multirow{2}{*}{0,024} \\
\hline Tidak Berisiko & 31 & 40,3 & 126 & 56,0 & 157 & 100 & \\
\hline \multicolumn{8}{|l|}{ Ketuban Pecah Dini } \\
\hline KPD & 49 & 63,6 & 103 & 45,8 & 175 & 100 & \multirow{2}{*}{0,010} \\
\hline Tidak KPD & 28 & 36,4 & 122 & 54,2 & 127 & 100 & \\
\hline \multicolumn{8}{|l|}{ Tekanan Darah } \\
\hline Hipertensi & 49 & 63,6 & 62 & 27,6 & 104 & 100 & \multirow{2}{*}{0,000} \\
\hline Tidak Hipertensi & 28 & 36,4 & 163 & 72,4 & 221 & 100 & \\
\hline
\end{tabular}




\section{Pembahasan}

\section{Hubungan paritas dengan BBLR}

Hasil penelitian menunjukkan ada hubungan antara paritas dengan BBLR (p-value 0,024). Hasil penelitian sejalan dengan hasil penelitian yang dilakukan oleh Supartini tahun 2012 di RSUD Ahmad Yani Kota Metro yang mengatakan bahwa ada hubungan yang bermakna antara paritas dengan kejadian BBLR ( $p$-value 0,000) (Supartini, 2012)

Ibu yang melahirkan 1 anak memiliki risiko gangguan reproduksi dimana alat reproduksi ibu belum matang. Pada ibu hamil dengan paritas $>3$, alat reproduksi yang dimiliki telah mengalami kemunduran daya lentur jaringan yang disebabkan terlalu sering melahirkan dengan usia yang berisiko menyebabkan terjadinya komplikasi dalam kehamilan dan persalinan (Winkjosastro, 2007). Pada kehamilan rahim ibu teregang oleh adanya janin, bila terlalu sering melahirkan rahim akan semakin lemah. Bila ibu melahirkan lebih dari 3 anak atau lebih maka dapat menimbulkan gangguan pertumbuhan janin pada waktu kehamilan seperti anemia, sehingga dapat melahirkan dengan BBLR dan perdarahan pada saat persalinan. Anemia dalam kehamilan merupakan salah satu penyebab terjadinya BBLR (Fraser \& cooper 2009). Anemia menyebabkan metabolisme dalam jaringan terganggu sehingga pertumbuhan janin tidak optimal dan dapat menimbulkan bayi dengan BBLR (Wulandari, 2013). Semakin tinggi paritas maka akan semakin tinggi risiko untuk kematian maternal maupun komplikasinya (Saifuddin, 2002).

Upaya yang dapat dilakukan tenaga kesehatan dengan penanganan ibu pada paritas satu dapat dilakukan konseling dengan menganjurkan ibu untuk rutin melakukan pemeriksaan kehamilan di tenaga kesehatan terdekat, sedangkan pada paritas tinggi dapat dikurangi atau dicegah dengan pemberian konseling pada ibu post partum dan menganjurkan ibu untuk rutin mengkonsumsi tablet Fe saat hamil.

\section{Hubungan KPD dengan BBLR}

Hasil analisis menunjukkan ada hubungan antara KPD dengan BBLR ( $p$-value 0,010). Hasil penelitian ini sama dengan hasil penelitian yang dilakukan oleh Humaeroh tahun 2014 di RSU PKU Muhammadiyah Bantul Yogyakarta yang mengatakan bahwa ada hubungan yang bermakna antara KPD dengan kejadian BBLR (p-value 0,008) (Humaeroh, 2014)

KPD merupakan pecahnya ketuban bila pembukaan pada primi kurang dari $3 \mathrm{~cm}$ dan pada multipara kurang dari $5 \mathrm{~cm}$ (Mochtar, 1998). KPD memiliki risiko terjadinya BBLR karena infeksi yang berasal dari vagina/ serviks menyebabkan terjadinya proses biomekanik pada selaput ketuban dalam bentuk proteolitik sel sehingga memudahkan terjadinya ketuban pecah (Yulaikhah, 2009). Pada kehamilan yang kurang bulan risiko terkait prematuritas lebih besar dari pada risiko infeksi setelah ketuban pecah dini. Prematuritas murni yaitu bila masa gestasi kurang dari 37 minggu dan berat badannya sesuai dengan berat badan untuk masa gestasi atau disebut juga neonatus kurang bulan sesuai untuk masa kehamilan (NKB-SMK). Bila kehamilan kurang dari 37 minggu maka risiko BBLR lebih besar daripada risiko infeksi setelah ketuban pecah dini (Varney, 2008).

Upaya yang dapat dilakukan tenaga kesehatan pada ibu bersalin dengan meningkatkan pemantauan pada ibu hamil yang mengalami KPD agar tidak terjadi infeksi setelah ketuban pecah dini dengan pemberian antibotik, pemantauan di rumah sakit hingga air ketuban tidak lagi keluar hingga mempertahankan kehamilannya dan melakukan pematangan paru-paru janin bila belum matang pada usia kurang bulan.

\section{Hubungan hipertensi dengan BBLR}

Penelitian memperoleh hasil ada hubungan antara KPD dengan BBLR (p-value 0,000). Hasil penelitian ini sama dengan hasil penelitian yang dilakukan oleh Afrina tahun 2013 di RSUD Ahmad 
Yani Kota Metro yang mengatakan bahwa adan hubungan hipertensi dengan kejadian BBLR (Aprina, 2013).

Hipertensi dalam kehamilan merupakan salah satu faktor risiko terjadinya kelahiran dengan BBLR. Pada hipertensi kehamilan tidak terjadi invasi sel-sel trofoblas pada lapisan otot arteri spiralis dan jaringan matriks sekitarnya. Lapisan otot arteri spiralis menjadi tetap kaku dan keras sehingga lumen arteri spiralis tidak mungkin mengalami distensi dan vasodilatasi, menyebabkan arteri spiralis relatif mengalami vasokontriksi, sehingga aliran darah uteroplasenta menurun, dan mengakibatkan mengakibatkan pertumbuhan janin terhambat atau iskemia plasenta (Wiknjosastro, 2014).

Vasokontriksi yang disebabkan oleh hipertensi dapat menurunkan aliran darah uterus, penurunan aliran darah ke ruang koriodesidua akan mengurangi jumlah oksigen yang berdifusi melalui sel sinsitiofoblas dan sititrofoblas ke dalam sirkulasi janin dalam plasenta, akibatnya jaringan plasenta menjadi iskemik atau terjadi infusiensi plasenta (Fraser \& cooper 2009), sehingga aliran yang menurun ke plasenta menyebabkan gangguan plasenta menyebabkan terjadi gangguan pertumbuhan janin (Mochtar, 1998).

Kejadian hipertensi dalam kehamilan pada ibu bersalin dapat meningkatkan risiko terjadinya BBLR, tenaga kesehatan diharapkan dapat melakukan penanganan dengan pemberian obat anti hipertensi dan pemeriksaan laboratorium untuk melihat adanya diagnosa komplikasi dari hipertensi serta pemantauan keadaan janin, serta memberikan konseling kepada ibu untuk melakukan pemantauan tekanan darah ke pelayanan kesehatan terdekat dan pemberian nutrisi yang adekuat pada bayi.

\section{Simpulan dan saran}

Hasil penelitian menyimpulkan BBLR berisiko meningkat berdasarkan paritas ibu, KPD pada ibu, dan hipertensi pada ibu dengan BBLR. Tenaga kesehatan perlu melakukan upaya menurunkan kejadian BBLR dengan peningkatan penatalaksanaan asuhan kepada ibu hamil melalui ante natal care khususnya pada ibu yang memiliki risiko paritas tinggi, ketuban pecah dini dan hipertensi.

\section{Referensi}

Afrina, N.N. (2013). Hubungan hipertensi dengan kejadian Berat Badan Lahir Rendah (BBLR) di RSUD Ahmad Yani Kota Metro Tahun 2012. Skripsi. Politeknik Kesehatan Tanjung Karang. Bandar Lampung: Tidak Dipublikasikan.

Dinkes Kota Metro. (2016). Profil kesehatan 2015 kota Metro. Kota Metro: Dinas Kesehatan Kota Metro.

Dinkes Provinsi Lampung. (2014). Profil kesehatan provinsi Lampung tahun 2013. Bandar Lampung: Dinkes Provinsi Lampung.

Fraser, D.M \& Cooper, M.A. (2009). Buku ajar bidan Myles. Jakarta: Penerbit Buku Kedokteran EGC.

Humaeroh, S. (2014). Hubungan ketuban pecah dini dengan kejadian BBLR di PKU Muhammadiyah Bantu. Retrieved from http//www.google.com). Tanggal 19 Desember 2016.

Kementrian Kesehatan RI. (2015). Profil kesehatan Indonesia tahun 2014. Jakarta: Kementerian Kesehatan RI.

Manuaba, I.B.G. (2010). Ilmu kebidanan, penyakit kandungan, dan keluarga berencan. Jakarta: Penerbit Buku Kedokteran EGC. .

Mochtar, R. (1998). Sinopsis obstetri. Jakarta: Buku Kedokteran EGC.

Rumah Sakit Mardi Waluyo Kota Metro. (2016). Rekam medik RS Mardi Waluyo Kota Metro. Kota Metro: Rumah Sakit Mardi Waluyo Kota Metro.

Saifuddin, A.B. (2009). Buku acuan nasional pelayanan kesehatan maternal dan neonatal. Jakarta: YBPSP.

Supartini, T. (2012). Hubungan paritas dan preeklamsia pada ibu bersalin dengan kejadian bayi baru lahir rendah di RSUD Jendral Ahmad Yani. Skripsi. Politeknik Kesehatan Tanjung Karang. Bandar Lampung: Tidak Dipubilasikan. 
Berat Bayi Lahir Rendah Berdasarkan Paritas, Ketuban Pecah Dini dan Hipertensi Septika Zahra, Prasetyowati, Yuliawati

Jurnal Kesehatan Metro Sai Wawai. 11 (1) 2018. E-ISSN 2657-1390. P-ISSN 19779-469X

Varney, H. (2007). Buku ajar asuhan kebidanan. Jakarta: Buku Kedokteran EGC.

Winkjosastro, H. (2014). Ilmu kebidanan. Jakarta: Yayasan Bina Pustaka.

Wulandari, R.E. (2013). Hubungan usia kehamilan dan paritas dengan kejadian BBLR di Rumah Sakit Umum Ahmad Yani Metro Tahun 2012. Skripsi. Politeknik Kesehatan Tanjung Karang. Bandar Lampung: Tidak Dipublikasikan.

Yulaikhah, L. (2009). Kehamilan: seri asuhan kebidanan. Jakarta: Penerbit Buku Kedokteran EGC. 